\title{
Exclusion of emphysematous lung from dose-volume estimates of risk improves prediction of radiation pneumonitis
}

\author{
Yasuki Uchida', Takuya Tsugawa², Sachiko Tanaka-Mizuno ${ }^{3,4}$, Kazuo Noma ${ }^{5}$, Ken Aoki ${ }^{2}$, Wataru Shigemori ${ }^{1}$, \\ Hiroaki Nakagawa', Daisuke Kinose', Masafumi Yamaguchi', Makoto Osawa ${ }^{1,6}$, Emiko Ogawa ${ }^{1,7}$ \\ and Yasutaka Nakano ${ }^{1 *}$
}

\begin{abstract}
Background: The risk factors for radiation pneumonitis (RP) in patients with chronic obstructive pulmonary disease (COPD) are unclear. Mean lung dose (MLD) and percentage of irradiated lung volume are common predictors of $\mathrm{RP}$, but the most accurate dosimetric parameter has not been established. We hypothesized that the total lung volume irradiated without emphysema would influence the onset of RP.

Methods: We retrospectively evaluated 100 patients who received radiotherapy for lung cancer. RP was graded according to the Common Terminology Criteria for Adverse Events (version 4.03). We quantified low attenuation volume (LAV) using quantitative computed tomography analysis. The association between RP and traditional dosimetric parameters including MLD, volume of the lung receiving a dose of $\geq 2 \mathrm{~Gy}, \geq 5 \mathrm{~Gy}, \geq 10 \mathrm{~Gy}$, $\geq 20 \mathrm{~Gy}$, and $\geq 30 \mathrm{~Gy}$, and counterpart measurements of the lung without LAV, were analyzed by logistic regression. We compared each dosimetric parameter for RP using multiple predictive performance measures including area under the receiver operating characteristic curve (AUC) and integrated discrimination improvement (IDI).

Results: Of 100 patients, RP of Grades 1, 2, 3, 4, and 5 was diagnosed in 24, 12, 13, 1, and 1 patients, respectively. Compared with traditional dosimetric parameters, counterpart measurements without LAV improved risk prediction of symptomatic RP. The ratio of the lung without LAV receiving $\geq 30 \mathrm{~Gy}$ to the total lung volume without LAV most accurately predicted symptomatic RP (AUC, 0.894; IDI, 0.064).
\end{abstract}

Conclusion: Irradiated lung volume without LAV predicted RP more accurately than traditional dosimetric parameters.

Keywords: Radiation pneumonitis, Chronic obstructive pulmonary disease, Low attenuation volume, Dosimetric parameter, Lung cancer

\section{Background}

Smoking is a major cause of both lung cancer and chronic obstructive pulmonary disease (COPD). Whether emphysematous lesion is a risk factor for radiation pneumonitis (RP) after radiotherapy (RT) is an important clinical problem, but the results obtained so far have been controversial. Some studies showed that COPD is a risk factor for RP [1-4], while others reported that RP was milder in patients

\footnotetext{
* Correspondence: nakano@belle.shiga-med.ac.jp

'Division of Respiratory Medicine, Department of Internal Medicine, Shiga University of Medical Science, Otsu, Shiga, Japan

Full list of author information is available at the end of the article
}

with more severe COPD than in patients with normal lung function $[5,6]$. There was also a report that COPD does not influence RP [7]. In that study, a scoring system similar to the modified Goddard system was used to evaluate the association between RP and emphysema [7], but could not assess the potential influence of emphysematous lesions within the irradiation field on RP. The relationship between RP and emphysematous lesions within the irradiation field has not been examined.

Mean lung dose (MLD) and the percentage of lung volume receiving 20 Gy or more (V20\%) are the most commonly recognized traditional dosimetric parameters 
associated with risk for RP [8-13]. However, a best dosimetric parameter for RP has not been determined.

The purposes of this study were twofold. First, to elucidate whether COPD is a risk factor for RP after RT in lung cancer patients, we examined the relationship between RP and dosimetric parameters associated with emphysematous lesions within the irradiation field. Second, we compared their predictive performances to determine which dosimetric parameter had the most predictive ability for RP.

\section{Materials and Methods \\ Selection of participants}

Patients who received RT for lung cancer at our institution between June 2010 and July $2015(N=100)$ were retrospectively selected. Inclusion criteria were predefined as follows: first time receiving RT; total irradiation dose >30 Gy; pneumonectomy not performed within 5 months after the RT or before the occurrence of symptomatic RP; follow-up period $>5$ months if symptomatic RP did not occur; and entire lung fields scanned using computed tomography $(\mathrm{CT})$ before RT.

\section{Radiotherapy planning and image analysis}

RT planning was done using Eclipse ${ }^{\mathrm{Tt}}$ software (Varian Medical Systems, Palo Alto, CA) with an analytical anisotropic algorithm. The distribution of radiation dose was calculated using lung heterogeneity corrections. Patients were treated with curative or palliative intent with RT alone or with concurrent chemoradiation. Ninety-five patients (Ninety-five percent) were treated with 3D conformal RT and five patients (5\%) were treated with intensity-modulated RT. The total dose varied between $30 \mathrm{~Gy}$ and $66 \mathrm{~Gy}$. CT scans were undertaken under free breathing before RT. Low attenuation volume (LAV), which represents emphysematous lesions in the lung, was evaluated using the threshold limit of $-856 \mathrm{HU}$ (Fig. 1a,b) [14]. We validated the association between the CT under free breathing and the inspiratory CT performed within 45 days after free breathing $\mathrm{CT}$. Inspiratory $\mathrm{CT}$ was performed using Toshiba Aquillion ONE (Toshiba Medical Systems Corp., Otawara, Tochigi, Japan) and LAV was analyzed using Aquarius iNtuition ${ }^{\text {tw }}$ software ver.4.4.12 (TeraRecon Inc., San Mateo, Calif) and evaluated using the threshold limit of $-950 \mathrm{HU}$. LAV was evaluated in both the right and left lungs. We also measured total lung volume (TLV) from the CT data, and the ratio of LAV to TLV (LAV\%) was calculated. The mean emphysema dose (MED) was defined as the mean dose of the irradiated LAV, and the mean lung without emphysema dose (MLWED) was defined as the mean dose of the irradiated TLV without LAV.
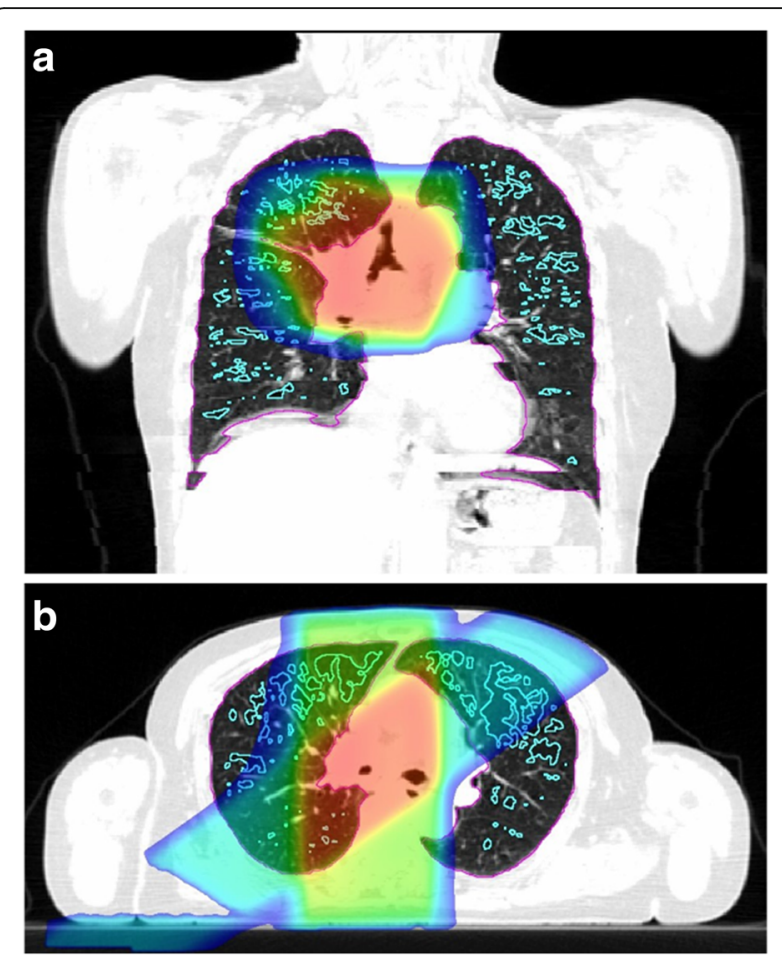

Fig. 1 The area inside the light blue line was the LAV and the threshold was $-856 \mathrm{HU}$. The area inside the purple line is the lung. The colorful area (for example red, yellow, green and blue) was the irradiated area and the overlaps were calculated

The dosimetric parameters we evaluated were listed in Table 1.

\section{Clinical toxicity}

Cases of RP were retrospectively monitored using the Common Terminology Criteria for Adverse Events, version 4.03 [15]. The primary endpoint for this analysis was symptomatic $\mathrm{RP} \geq$ Grade 2, and the secondary endpoint was $R P \geq$ Grade 3 . Patients were generally followed for 3 to 6 weeks after completion of RT, and at 3- to 6-month intervals thereafter. A diagnosis of RP was made on the basis of radiographic images, laboratory tests, physical examination, clinical symptoms, and medical records.

The study protocol was approved by the Institutional Review Board, which waived written informed consent because of the retrospective design.

\section{Statistical analysis}

We used summary statistics to analyze clinical factors including age, sex, disease stage, histology type, type of RT, chemotherapy, smoking history, smoking index, body mass index (BMI), and interstitial lung disease (ILD) for all patients, and classified patients as symptomatic RP, and $\mathrm{RP} \geq$ Grade 3. For description, we used median and range for continuous variables, and 
Table 1 Evaluated dosimetric parameters

\begin{tabular}{|c|c|}
\hline Parameter & \\
\hline V2 (cc) & The volume of the lung receiving a dose $\geq 2 \mathrm{~Gy}$ \\
\hline V5 (cc) & The volume of the lung receiving a dose $\geq 5 \mathrm{~Gy}$ \\
\hline $\mathrm{V} 10(\mathrm{cc})$ & The volume of the lung receiving a dose $\geq 10 \mathrm{~Gy}$ \\
\hline $\mathrm{V} 20(\mathrm{cc})$ & The volume of the lung receiving a dose $\geq 20$ Gy \\
\hline V30 (cc) & The volume of the lung receiving a dose $\geq 30$ Gy \\
\hline $\mathrm{V} 2-\mathrm{LAV} 2(\mathrm{cc})$ & $\begin{array}{l}\text { The volume of the lung without } L A V \text { receiving a } \\
\text { dose of } \geq 2 \text { Gy }\end{array}$ \\
\hline V5 - LAV5 (cc) & $\begin{array}{l}\text { The volume of the lung without LAV receiving a } \\
\text { dose of } \geq 5 \mathrm{~Gy}\end{array}$ \\
\hline V10 - LAV10 (cc) & $\begin{array}{l}\text { The volume of the lung without LAV receiving a } \\
\text { dose of } \geq 10 \mathrm{~Gy}\end{array}$ \\
\hline V20 - LAV20 (cc) & $\begin{array}{l}\text { The volume of the lung without } L A V \text { receiving a } \\
\text { dose of } \geq 20 \mathrm{~Gy}\end{array}$ \\
\hline V30 - LAV30 (cc) & $\begin{array}{l}\text { The volume of the lung without } L A V \text { receiving a } \\
\text { dose of } \geq 30 \mathrm{~Gy}\end{array}$ \\
\hline LAV2 (cc) & The volume of $L A V$ receiving a dose of $\geq 2 \mathrm{~Gy}$ \\
\hline LAV5 (cc) & The volume of $L A V$ receiving a dose of $\geq 5$ Gy \\
\hline LAV10 (cc) & The volume of $L A V$ receiving a dose of $\geq 10 \mathrm{~Gy}$ \\
\hline LAV20 (cc) & The volume of $L A V$ receiving a dose of $\geq 20 \mathrm{~Gy}$ \\
\hline LAV30 (cc) & The volume of $L A V$ receiving a dose of $\geq 30 \mathrm{~Gy}$ \\
\hline V2\% & The percentage of lung volume receiving $\geq 2 \mathrm{~Gy}$ \\
\hline V5\% & The percentage of lung volume receiving $\geq 5$ Gy \\
\hline$\vee 10 \%$ & The percentage of lung volume receiving $\geq 10 \mathrm{~Gy}$ \\
\hline V20\% & The percentage of lung volume receiving $\geq 20 \mathrm{~Gy}$ \\
\hline V30\% & The percentage of lung volume receiving $\geq 30 \mathrm{~Gy}$ \\
\hline$(\mathrm{V} 2-\mathrm{LAV} 2) / \mathrm{TLV}$ & $\begin{array}{l}\text { The ratio of the lung without } L A V \text { receiving } \\
\geq 2 \text { Gy to the TLV }\end{array}$ \\
\hline$(V 5-L A V 5) / T L V$ & $\begin{array}{l}\text { The ratio of the lung without } L A V \text { receiving } \\
\geq 5 \text { Gy to the TLV }\end{array}$ \\
\hline$(V 10-L A V 10) / T L V$ & $\begin{array}{l}\text { The ratio of the lung without } L A V \text { receiving } \\
\geq 10 \text { Gy to the TLV }\end{array}$ \\
\hline (V20 - LAV20) / TLV & $\begin{array}{l}\text { The ratio of the lung without } L A V \text { receiving } \\
\geq 20 \text { Gy to the } T L V\end{array}$ \\
\hline (V30 - LAV30) / TLV & $\begin{array}{l}\text { The ratio of the lung without } L A V \text { receiving } \\
\geq 30 \text { Gy to the TLV }\end{array}$ \\
\hline$(V 2-L A V 2) /(T L V-L A V)$ & $\begin{array}{l}\text { The ratio of the lung without } L A V \text { receiving } \\
\geq 2 \text { Gy to the TLV without } L A V\end{array}$ \\
\hline (V5 - LAV5) / (TLV - LAV) & $\begin{array}{l}\text { The ratio of the lung without } L A V \text { receiving } \\
\geq 5 \text { Gy to the TLV without } L A V\end{array}$ \\
\hline (V10 - LAV10) / (TLV - LAV) & $\begin{array}{l}\text { The ratio of the lung without } L A V \text { receiving } \\
\geq 10 \text { Gy to the } T L V \text { without } L A V\end{array}$ \\
\hline (V20 - LAV20) / (TLV - LAV) & $\begin{array}{l}\text { The ratio of the lung without LAV receiving } \\
\geq 20 \text { Gy to the TLV without LAV }\end{array}$ \\
\hline (V30 - LAV30) / (TLV - LAV) & $\begin{array}{l}\text { The ratio of the lung without LAV receiving } \\
\geq 30 \text { Gy to the TLV without LAV }\end{array}$ \\
\hline LAV (cc) & Low attenuation volume \\
\hline LAV\% & The ratio of $L A V$ to the total lung volume \\
\hline $\mathrm{TLV}-\mathrm{LAV}(\mathrm{cc})$ & Total lung volume without LAV \\
\hline MLD (Gy) & Mean lung dose \\
\hline MED (Gy) & Mean dose of the irradiated LAV, \\
\hline MLWED (Gy) & Mean lung without emphysema dose \\
\hline
\end{tabular}

percentage for categorical variables. We also compared the clinical factors between $\mathrm{RP} \geq$ Grade 2 and $\mathrm{RP} \leq$ Grade 1, and between RP $\geq$ Grade 3 and $R P \leq$ Grade 2, using Wilcoxon's rank sum test or Fisher's exact test.

Traditional dosimetric parameters including MLD, V2\%, V5\%, V10\%, V20\%, and V30\%, and other dosimetric parameters associated with $\mathrm{LAV}$, were described with median and interquartile range.

Multivariable logistic regression was conducted to evaluate the association between each dosimetric parameter and the onset of symptomatic RP, or RP $\geq$ Grade 3 . Dosimetric parameters were divided by the standard deviation of each. The adjusted factors were decided using the result of univariate analysis. The predictive performance of each dosimetric parameter for RP was compared using the area under the receiver operating characteristic curve (AUC), Akaike's information criterion (AIC), Bayesian information criterion (BIC), integrated discrimination improvement (IDI), and the net reclassification improvement (NRI). For IDI and NRI, the model with MLD was used as a reference model. We required a $p$ value $<0.05$ for statistical significance. Statistical analyses were performed using JMP version 11 (SAS Institute Inc., Cary, NC) and SAS software version 9.4 (SAS Institute Inc., Cary, NC).

\section{Results}

\section{Clinical parameters}

RP was observed in 51 out of 100 patients: Grade 1, 24 patients; Grade 2, 12 patients; Grade 3, 13 patients; Grade 4, one patient; and Grade 5, one patient. Forty-nine patients did not develop RP. Therefore, in total, 27 patients developed $\mathrm{RP} \geq$ Grade 2 and 15 patients developed $\mathrm{RP} \geq$ Grade 3 .

The follow-up period after the onset of RP was between 1 and 60 months (median, 12 months). Six patients died from lung cancer or RP, and one patient was referred to another hospital, after the onset of symptomatic RP and within 5 months of receiving RT. The period of observed onset of symptomatic RP was between 2 days and 8 months (median, 1 month) after RT.

Tables 2 and 3 show the results of univariate analysis. In the univariate analysis, disease stage (Stage 3), chemotherapy, ILD, MLD, and V20\% were significantly associated with the occurrence of symptomatic RP (Table 2). None of the chemotherapy regimens were significantly associated with the occurrence of symptomatic RP $(P=0.599)$. Thirty-six patients received chemotherapy and RT concurrently, and four patients received chemotherapy before RT. If we limit $R P \geq$ Grade 3, staging (Stage 3), chemotherapy, ILD, and histology type were significantly associated with the occurrence of RP in the univariate analysis (Table 3). 
Table 2 Clinical parameters in symptomatic radiation pneumonitis patients and asymptomatic patients

\begin{tabular}{|c|c|c|c|c|}
\hline Characteristic & $\begin{array}{l}\text { Total No. of Patients } \\
(N=100)\end{array}$ & $\begin{array}{l}\text { No. of Symptomatic Patients } \\
\text { ( } \geq \text { grade } 2 \text { RP) }(N=27)\end{array}$ & $\begin{array}{l}\text { No. of Asymptomatic Patients } \\
\text { ( } \leq \text { grade } 1 \text { RP) }(N=73)\end{array}$ & $P$ Value \\
\hline Median age (range), y & 72 (39-89) & 70 (59-82) & 73 (39-89) & 0.248 \\
\hline Male sex & $82(82)$ & $25(92.6)$ & $57(80.3)$ & 0.221 \\
\hline Disease stage & & & & 0.003 \\
\hline 1 & $25(25)$ & $1(3.7)$ & $24(32.9)$ & \\
\hline 2 & $9(9)$ & $2(7.4)$ & $7(9.6)$ & \\
\hline 3 & $51(51)$ & $21(77.8)$ & $30(41.1)$ & \\
\hline 4 & $15(15)$ & $3(11.1)$ & $12(16.4)$ & \\
\hline${ }^{a}$ Histology type & & & & 0.060 \\
\hline $\mathrm{SqCC}$ & $33(33)$ & $12(44.4)$ & $21(28.8)$ & \\
\hline Adenocarcinoma & $27(27)$ & $5(18.5)$ & $22(30.1)$ & \\
\hline SCC & $15(15)$ & $7(25.9)$ & $8(11.0)$ & \\
\hline NSCC & $8(8)$ & $2(7.4)$ & $6(8.2)$ & \\
\hline Unknown & $14(14)$ & $1(3.7)$ & $13(17.8)$ & \\
\hline Others & $3(3)$ & $0(0)$ & $3(4.1)$ & \\
\hline Treatment type & & & & 0.103 \\
\hline IMRT & $5(5)$ & $0(0)$ & $5(6.8)$ & \\
\hline 3D Conformal & $95(95)$ & $27(100)$ & $68(93.2)$ & \\
\hline Chemotherapy & & & & $<0.0001$ \\
\hline Yes & $40(40)$ & $20(74.1)$ & $20(27.4)$ & \\
\hline No & $60(60)$ & $7(25.9)$ & $53(72.6)$ & \\
\hline Smoking history & & & & 0.196 \\
\hline Current & $24(24)$ & $10(37.0)$ & $14(19.2)$ & \\
\hline Former & $59(59)$ & $13(48.2)$ & $46(63.0)$ & \\
\hline Never & $17(17)$ & $4(14.8)$ & $12(17.8)$ & \\
\hline Smoking (range), pack-years & $40(0-180)$ & $45(0-120)$ & $36(0-180)$ & 0.195 \\
\hline Median BMI (range), kg/m² & $20.3(14.98-27.40)$ & $20.55(16.19-24.83)$ & $20.16(14.98-27.40)$ & 0.395 \\
\hline ILD & & & & 0.0358 \\
\hline Yes & $6(6)$ & $4(14.8)$ & $2(2.7)$ & \\
\hline No & $94(94)$ & $23(85.2)$ & $71(97.3)$ & \\
\hline Surgery & & & & 0.3142 \\
\hline None & $95(95)$ & 25 (92.6) & 70 (95.9) & \\
\hline Pre-RT & $1(1)$ & $1(3.7)$ & $0(0)$ & \\
\hline Post-RT & $4(4)$ & $1(3.7)$ & $3(4.1)$ & \\
\hline Median MLD (IQR), Gy & $7.2(3.676-10.572)$ & $11.416(8.615-16.801)$ & $4.854(3.338-8.146)$ & $<0.0001$ \\
\hline Median V20\% (IQR) & $13.554(5.872-20.449)$ & $21.153(17.092-30.368)$ & $10.314(4.802-14.529)$ & $<0.0001$ \\
\hline Median LAV\% (IQR) & $0.103(0.026-0.257)$ & $0.095(0.037-0.254)$ & $0.108(0.018-0.279)$ & 0.907 \\
\hline
\end{tabular}

(Wilcoxon's rank sum test or Fisher's exact test)

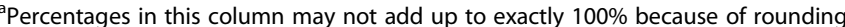

Unless otherwise specified, data are expressed as numbers of patients, and numbers in parentheses are percentages. $\mathrm{RP}=$ radiation pneumonitis; $\mathrm{SqCC}=\mathrm{squamous}$ cell carcinoma; SCC = small cell carcinoma; NSCC = non-small cell carcinoma; IMRT = intensity-modulated radiotherapy; BMI = body mass index; ILD = interstitial lung disease; $M L D=$ mean lung dose; $I Q R=$ interquartile range; $V 20 \%=$ percentage of lung volume irradiated $\geq 20 \mathrm{~Gy} ; \mathrm{LAV} \%=$ ratio of low attenuation volume to the lung volume

\section{Dose volume parameter}

Thirty-three patients underwent inspiratory CT within 45 days after free-breathing CT under the same condition. The LAV in inspiratory CT was highly correlated with the
LAV in CT under free breathing (Fig. 2). Since patients who received chemotherapy were almost equal to the patients of disease stage 3, chemotherapy and interstitial lung disease (ILD) were used as adjusted factors in the logistic 
Table 3 Clinical parameters in patients with radiation pneumonitis $\geq$ Grade 3 and $\leq$ Grade 2

\begin{tabular}{|c|c|c|c|}
\hline Characteristic & $\begin{array}{l}\text { Total No. of Patients } \\
(N=100)\end{array}$ & $\begin{array}{l}\text { No. of } \geq \text { Grade } 3 \text { RP Patients } \\
(N=15)\end{array}$ & $\begin{array}{l}\text { No. of } \leq \\
(N=85)\end{array}$ \\
\hline Median age (range), y & $72(39-89)$ & $71(62-80)$ & $72(39-\varepsilon$ \\
\hline Male sex & $82(82)$ & $14(93.3)$ & \\
\hline \multicolumn{4}{|l|}{ Disease stage } \\
\hline 1 & $25(25)$ & $0(0)$ & $25(29.4)$ \\
\hline 2 & $9(9)$ & $2(13.3)$ & $7(8.2)$ \\
\hline 3 & $51(51)$ & $11(73.3)$ & $40(47.1)$ \\
\hline 4 & $15(15)$ & $2(13.3)$ & $13(15.3)$ \\
\hline \multicolumn{4}{|l|}{ a Histology type } \\
\hline SqCC & $33(33)$ & $10(66.7)$ & $23(27.1)$ \\
\hline Adenocarcinoma & $27(27)$ & $2(13.3)$ & $25(29.4)$ \\
\hline SCC & $15(15)$ & $3(20.0)$ & $12(14.1)$ \\
\hline NSCC & $8(8)$ & $0(0)$ & $8(9.4)$ \\
\hline Unknown & $14(14)$ & $0(0)$ & $14(16.4)$ \\
\hline Others & $3(3)$ & $0(0)$ & $3(3.5)$ \\
\hline \multicolumn{4}{|l|}{ Treatment type } \\
\hline IMRT & $5(5)$ & $0(0)$ & $5(5.9)$ \\
\hline 3D Conformal & $95(95)$ & $15(100)$ & $80(94.1)$ \\
\hline \multicolumn{4}{|l|}{${ }^{\mathrm{a} C h e m o t h e r a p y ~}$} \\
\hline Yes & $40(40)$ & $11(73.3)$ & $29(34.1)$ \\
\hline No & $60(60)$ & $4(26.7)$ & $56(65$ \\
\hline
\end{tabular}

Smoking history

Current

Former

$24(24)$

59 (59)

Never

Smoking (range), pack-years

Median BMI (range), $\mathrm{kg} / \mathrm{m}^{2}$

17 (17)

40 (0-180)

20.30

(14.98-27.40)

alLD

$\begin{array}{ll}\text { Yes } & 6(6) \\ \text { No } & 94(94)\end{array}$

Surgery

No surgery
Pre-RT
Post-RT

Median MLD (IQR), Gy

Median V20\% (IQR)

Median LAV\% (IQR)

Median LAV\% (IQR)

\section{4 (94)}

95 (95)

4 (4)

7.200

(3.676-10.572)

13.554

(5.872-20.449)

0.103

(0.026-0.257)
0.0479

$1(6.7)$
$12(80.0)$

2 (13.3)

$52(0-120)$

20.91

(16.19-24.83)

$3(20.0)$

$12(80.0)$
$P$ Value

0.988

0.453

0.0398

5 (29.4)

(8.2)

$3(15.3)$

3 (27.1)

$2(14.1)$

(9.4)

$4(16.4)$

1.000

0.0082

6 (65.9)

$23(27.1)$

$47(55.3)$

15 (17.6)

39 (0-180)

0.118

19.98

0.126

(14.98-27.40)

0.0420

3 (3.5)

$82(96.5)$

0.0783

$$
\begin{array}{r}
13(86.7) \\
1(6.7)
\end{array}
$$

$1(6.7)$

10.717

(8.590-17.610)

20.522

(15.336-27.924)

0.085

(0.035-0.254)
$82(96.5)$

$$
0(0)
$$$$
3(3.5)
$$

5.896

$<0.0001$

$$
(3.474-9.308)
$$

12.626

$<0.0001$

(5.039-18.328)

0.112

(Wilcoxon's rank sum test or Fisher's exact test)

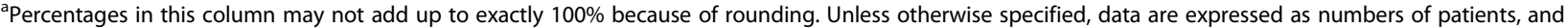
numbers in parentheses are percentages. RP = radiation pneumonitis; SqCC = squamous cell carcinoma; $\mathrm{SCC}=$ small cell carcinoma; NSCC = non-small cell carcinoma; IMRT = intensity-modulated RT; BMI = body mass index; ILD = interstitial lung disease; MLD = mean lung dose; V20\% = percentage of lung volume irradiated with $\geq 20 \mathrm{~Gy} ; \mathrm{IQR}=$ interquartile range; $\mathrm{LAV} \%=$ ratio of $\mathrm{LAV}$ to total lung volume 
models. Multivariable logistic regression analysis for symptomatic RP ( $\geq$ Grade 2 ) demonstrated that none of the dosimetric parameters that included LAV (i.e. LAV2, LAV5, LAV10, LAV20, LAV30, LAV, LAV\%, and TLV - LAV) were significantly related to symptomatic RP (Table 4). Irradiated lung volume (V2, V5, V10, V20, V30) and counterpart measurements of the lung without LAV (V2 - LAV2, V5 - LAV5, V10 - LAV10, V20 - LAV20, V30 - LAV30) all were significantly associated with the occurrence of symptomatic RP. Every irradiated lung volume measurement without an LAV parameter (V2 - LAV2, V5 - LAV5, V10 - LAV10, V20 - LAV20, V30 - LAV30) had lower $p$ values and higher odds ratios than the counterpart values with LAV (V2, V5, V10, V20, V30), indicating a stronger association with symptomatic RP. The percentage of irradiated lung volume (V2\%, V5\%, V10\%, V20\%, V30\%) and counterpart measurements of the lung without LAV were also significantly associated with the occurrence of symptomatic RP. The MLD, MED, and MLWED all were significantly associated with the occurrence of symptomatic RP; however, a comparison of $p$ values and odds ratios between the three parameters suggested a stronger association between MLWED and the occurrence of symptomatic RP.

In multivariable logistic regression analysis for $R P \geq$ Grade 3, the results were very similar to those for symptomatic RP, i.e., all of the dosimetric parameters except V2, V5, V10, and MED were significantly related to $\mathrm{RP} \geq$ Grade 3 (Additional file 1).

The predictive performance of dosimetric parameters for symptomatic RP was compared using AUC, AIC, BIC, IDI, and NRI (Fig. 3). The parameters with smaller AIC value or smaller BIC value are preferable when comparing two or more parameters. The parameters with bigger AUC value, IDI value, or NRI value are

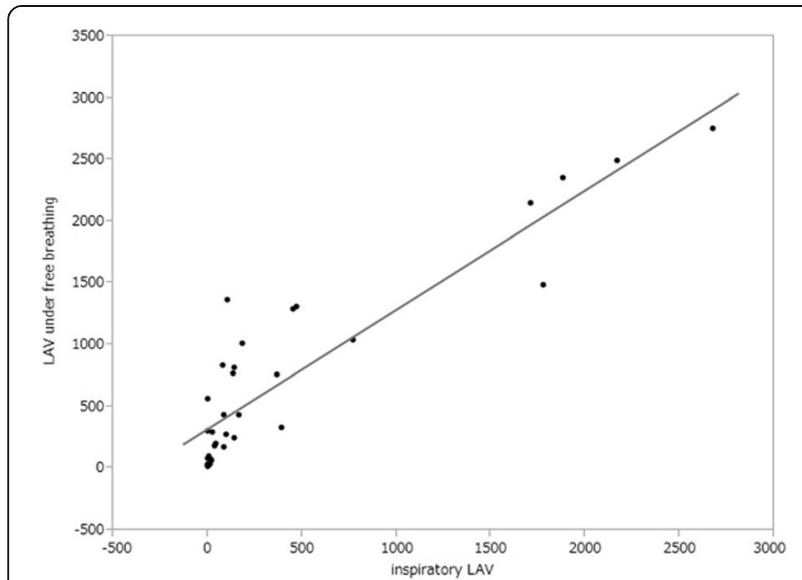

Fig. 2 Spearman rank correlations between the LAV in inspiratory CT and the LAV in CT under free breathing in 33 patients. There was a significant relationship between these two measurements (LAV in CT under free breathing $=0.97 \times L A V$ in inspiratory $C T+322.5$, $r=0.839, P<.0001)$
Table 4 Multivariate logistic regression analysis for symptomatic radiation pneumonitis ( $\geq$ Grade 2 )

\begin{tabular}{|c|c|c|}
\hline Parameter & Odds ratio & $P$ Value \\
\hline V2 (cc) & $1.768(1.056-3.104)$ & 0.0358 \\
\hline V5 (cc) & $1.795(1.071-3.160)$ & 0.0315 \\
\hline V10 (cc) & $2.034(1.196-3.710)$ & 0.0122 \\
\hline V20 (cc) & 2.270 (1.309-4.287) & 0.0057 \\
\hline V30 (cc) & $2.621(1.482-5.055)$ & 0.0018 \\
\hline V2 - LAV2 (cc) & $2.037(1.175-3.827)$ & 0.0168 \\
\hline V5 - LAV5 (cc) & $2.098(1.192-4.054)$ & 0.0164 \\
\hline V10 - LAV10 (cc) & $2.451(1.344-5.011)$ & 0.0071 \\
\hline V20 - LAV20 (cc) & $2.900(1.525-6.228)$ & 0.0028 \\
\hline V30 - LAV30 (cc) & $3.627(1.852-7.960)$ & 0.0005 \\
\hline LAV2 (cc) & $1.058(0.618-1.718)$ & 0.823 \\
\hline LAV5 (cc) & $1.059(0.615-1.702)$ & 0.822 \\
\hline LAV10 (cc) & $1.118(0.650-1.775)$ & 0.650 \\
\hline LAV20 (cc) & $1.143(0.666-1.791)$ & 0.578 \\
\hline LAV30 (cc) & $1.116(0.640-1.742)$ & 0.652 \\
\hline V2\% & $2.535(1.422-4.935)$ & 0.0030 \\
\hline V5\% & $2.421(1.360-4.690)$ & 0.0047 \\
\hline V10\% & 2.957 (1.586-6.188) & 0.0016 \\
\hline V20\% & $3.771(1.897-8.671)$ & 0.0005 \\
\hline V30\% & $4.996(2.392-12.299)$ & $<0.0001$ \\
\hline$(\mathrm{V} 2-\mathrm{LAV} 2) / \mathrm{TLV}$ & 2.467 (1.384-4.792) & 0.0040 \\
\hline (V5 - LAV5) / TLV & $2.376(1.337-4.168)$ & 0.0054 \\
\hline (V10 - LAV10) / TLV & $2.913(1.558-6.096)$ & 0.0019 \\
\hline (V20 - LAV20) / TLV & 4.085 (1.984-9.865) & 0.0005 \\
\hline (V30 - LAV30) / TLV & $6.114(2.726-16.873)$ & $<0.0001$ \\
\hline$(\mathrm{V} 2-L A V 2) /(T L V-L A V)$ & $2.810(1.551-5.621)$ & 0.0015 \\
\hline (V5 - LAV5) / (TLV - LAV) & $2.788(1.532-5.606)$ & 0.0017 \\
\hline (V10 - LAV10) / (TLV - LAV) & $3.363(1.756-7.632)$ & 0.0008 \\
\hline$($ V20 - LAV20) / (TLV - LAV) & $4.319(2.118-10.368)$ & 0.0003 \\
\hline$(\mathrm{V} 30$ - LAV30) / (TLV - LAV) & $5.707(2.676-14.706)$ & $<0.0001$ \\
\hline LAV (cc) & $0.758(0.378-1.351)$ & 0.383 \\
\hline LAV\% & $0.901(0.489-1.571)$ & 0.722 \\
\hline TLV - LAV (cc) & $0.869(0.491-1.492)$ & 0.617 \\
\hline MLD (Gy) & 3.615 (1.893-7.836) & 0.0003 \\
\hline MED (Gy) & $1.906(1.154-3.270)$ & 0.0138 \\
\hline MLWED (Gy) & $3.950(2.042-8.746)$ & 0.0002 \\
\hline
\end{tabular}

The number of symptomatic RP patients / Total patients was 27 / 100 Data were divided by the standard deviation and adjusted for chemotherapy and interstitial lung disease. V2/5/10/20/30 = volume of the lung receiving a dose $\geq 2 / 5 / 10 / 20 / 30 \mathrm{~Gy}$, respectively; $\mathrm{V} 2 / 5 / 10 / 20 / 30 \%=$ percentage of lung volume irradiated with $\geq 2 / 5 / 10 / 20 / 30 \mathrm{~Gy}$, respectively; LAV2/5/10/20/30 = volume of the lung without low attenuation volume (LAV) receiving $2 / 5 / 10 / 20 / 30 \mathrm{~Gy}$, respectively; TLV = total lung volume; $M L D=$ mean lung dose; $M E D=$ mean emphysema dose; $M L W E D=$ mean lung without emphysema dose 
preferable when comparing two or more parameters. The same tendency was shown in all statistical measures. The irradiated lung volume (V2, V5, V10, V20, V30) showed a lower predictive performance for symptomatic RP than the counterpart measurements of the lung without LAV (V2 - LAV2, V5 - LAV5, V10 - LAV10, V20 - LAV20, V30 - LAV30). MLWED predicted the risk of symptomatic RP more accurately than MLD. For every lung volume measurement, the ratio of the irradiated lung volume without LAV to the TLV without LAV [(V2 - LAV2) / (TLV - LAV), (V5 LAV5) / (TLV - LAV), (V10 - LAV10) / (TLV - LAV), (V20 - LAV20) / (TLV - LAV), (V30 - LAV30) / (TLV LAV)] predicted the risk of symptomatic RP more accurately than the conventional dosimetric parameters, including the V2\%, V5\%, V10\%, V20\%, and V30\% counterparts. The most accurate dosimetric predictor of symptomatic $\mathrm{RP}$ was the ratio of the lung without LAV receiving $\geq 30$ Gy
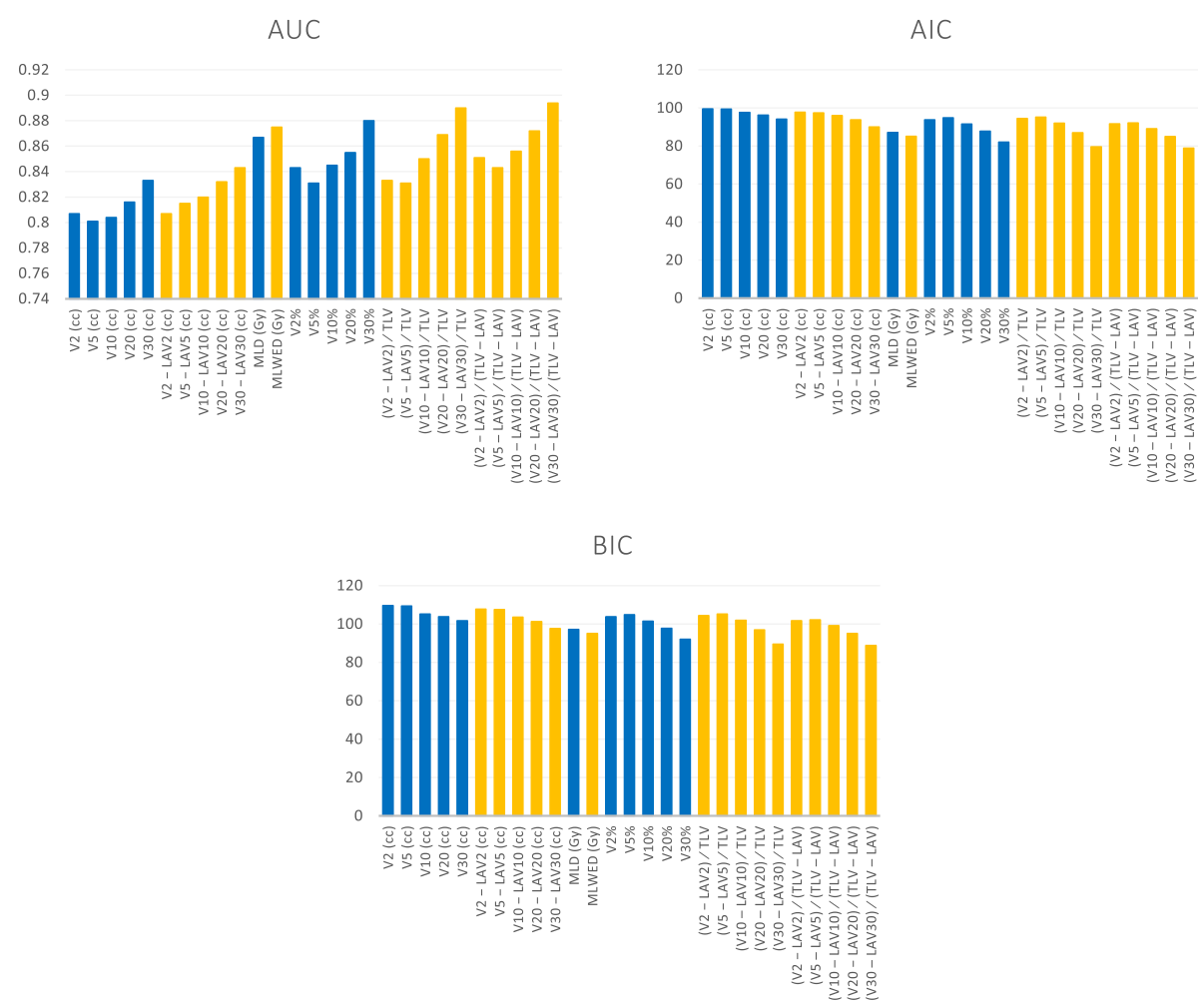

IDI

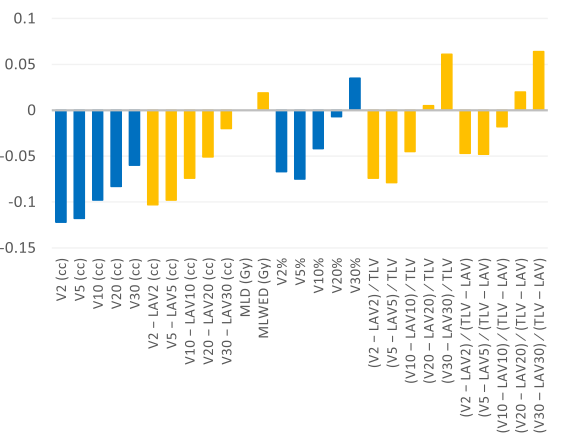

NRI

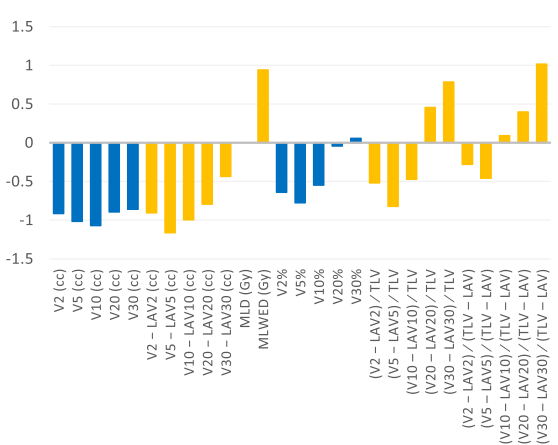

Fig. 3 The parameters with smaller AIC value or smaller BIC value are preferable. The parameters with bigger AUC value, IDI value, or NRI value are preferable. Compared with traditional dosimetric parameters (blue bar), counterpart measurements without LAV (orange bar) improved risk prediction of symptomatic RP. Data were adjusted for chemotherapy and interstitial lung disease. AUC = difference in the area under the receiver operating characteristic curve; $\mathrm{V} 2 / 5 / 10 / 20 / 30=$ volume of the lung receiving a dose $\geq 2 / 5 / 10 / 20 / 30 \mathrm{~Gy}$, respectively; V2/5/10/20/30\%= percentage of lung volume irradiated with $\geq 2 / 5 / 10 / 20 / 30 \mathrm{~Gy}$, respectively; $L A V 2 / 5 / 10 / 20 / 30=$ volume of the lung without low attenuation volume (LAV) receiving 2/5/10/20/30 Gy, respectively; TLV= total lung volume; $M L D=$ mean lung dose; $M E D=$ mean emphysema dose; $M L W E D=$ mean lung without emphysema dose 
to the TLV without LAV (AIC, 78.849; BIC, 88.848; AUC, 0.894; IDI, 0.064; NRI, 1.016). According to the receiver operating characteristic analysis, the threshold value of the (V30 - LAV30) / (TLV - LAV) predictor was 0.161 (sensitivity, $74.1 \%$; specificity, $91.8 \%$ ).

\section{Discussion}

In this study, we compared various parameters to identify the best predictor for RP in lung cancer patients. First, we found that the absolute lung volume inside the irradiation field was correlated with the occurrence of symptomatic RP ( $\geq$ Grade 2 ). It has been well established that the percentage of irradiated lung volume is correlated with the occurrence of RP $[9,13,16]$. Tsujino et al. proposed that absolute lung volume spared from 5 Gy is significantly associated with RP [7], but absolute lung volume inside the irradiation field has not been evaluated until now. Second, irradiated lung volume without LAV was a better dosimetric predictor of RP than irradiated lung volume including LAV. Third, we identified a new dosimetric parameter that was the most accurate predictor of symptomatic RP: (V30 - LAV30)/ (TLV - LAV). These findings suggest that the total amount of the lung volume without emphysematous lesions inside the radiation field might influence the onset of RP.

Various dosimetric parameters including MLD and V20\% have been reported to predict RP $[9,11,13,16,17]$. The dosimetric parameters analyzed in this study were mutually correlated, therefore we used AUC, AIC, BIC, IDI, and NRI to compare them for RP predictive power. To our knowledge, this is the first report using multiple statistical measures to determine the strongest predictor for RP.

Takeda et al. reported that heavy smoking is the strongest negative predictor of severe RP and is correlated with severe COPD [5]. Wang et al. also noted that lower baseline pulmonary function did not increase the risk of symptomatic radiation-induced lung toxicity [6]. Our results are in line with these reports. Studies of bronchoalveolar lavage in human subjects, and bronchoalveolar lavage and ultrastructural morphology in animal models, also demonstrated that there is less inflammation in the alveolar tissue in those irradiated and exposed to smoking than in those irradiated but not exposed to smoking $[18,19]$.

By contrast, other authors have argued that COPD and severe pulmonary emphysema are significant risk factors for RP $[1,2]$. Inoue et al. investigated the relationship between the diagnosis of COPD and RP [1]. They did not find any association between emphysema volume inside the irradiation volume and RP. However, because the diagnosis of COPD in their report was based on the forced expiratory volume in $1 \mathrm{~s}\left(\mathrm{FEV}_{1}\right) /$ forced vital capacity $(\mathrm{FVC})<0.70$ ratio, the degree of emphysematous lesions, and especially early changes in the lung, were not evaluated using CT. A prospective study is currently underway to investigate the similar concept of the present study [20].

Chemotherapy regimens including carboplatin/paclitaxel and ILD have also been reported as risk factors for RP [3, 7, 21-23]. In the present study, chemotherapy and ILD were significantly associated with the occurrence of symptomatic RP. Therefore, we thought these factors might be confounding factors and chemotherapy and ILD were used as adjusted factors in the logistic models in this study.

The threshold used for quantification of emphysema is generally $-950 \mathrm{HU}$, which is appropriate for use at full inspiration [24, 25]. In the present study, CT scanning was conducted under free breathing, which is nearly equal to expiratory $\mathrm{CT}$; therefore, we used the $-856 \mathrm{HU}$ threshold $[14,26-29]$. We also validated that the LAV in inspiratory $C T$ was highly correlated with the LAV in CT under free breathing (Fig. 2).

This study had several limitations that warrant further evaluation. First, our subjects were relatively small in number and came from a single institution. This was also a retrospective study. A prospective multicenter study is needed to confirm the results. Second, we did not evaluate ILD quantitatively; however, it should be noted that currently there is no established method for quantitative evaluation of ILD. Third, because many values were missing, we were unable to evaluate pulmonary function tests. Forth, the large number of simultaneous independent variables were used for multivariate logistic regression in comparison to the sample size. Therefore they can be prone to overfitting.

\section{Conclusions}

We conclude that use of irradiated lung volume without emphysema leads to more accurate dosimetric prediction of RP than traditional parameters. The most accurate dosimetric predictor of RP was the ratio of the lung without LAV receiving $\geq 30$ Gy to the TLV without LAV.

\section{Additional file}

Additional file 1: Table S1. Multivariate logistic regression analysis for radiation pneumonitis $\geq$ Grade 3 . (DOCX $19 \mathrm{~kb}$ )

\section{Abbreviations}

AIC: Akaike's information criterion; AUC: Area under the receiver operating characteristic curve; BIC: Bayesian information criterion; BMI: Body mass index; COPD: Chronic obstructive pulmonary disease; CT: Computed tomography; G2: Grade 2; G3: Grade 3; IDI: Integrated discrimination improvement; ILD: Interstitial lung disease; IMRT: Intensity-modulated radiotherapy; LAV: Low attenuation volume; LAV\%: The percentage of low attenuation volume to total lung volume; MED: Mean emphysema dose; MLD: Mean lung dose; MLWED: Mean lung without emphysema dose; 
NRI: Net reclassification improvement; RP: Radiation pneumonitis; RT: Radiotherapy; TLV: Total lung volume; V2: The volume of the lung receiving a dose of $\geq 2 \mathrm{~Gy}$; $V_{5}$ : The volume of the lung receiving a dose of $\geq 5 \mathrm{~Gy}$; $\mathrm{V} 10$ : The volume of the lung receiving a dose of $\geq 10 \mathrm{~Gy}$; V20: The volume of the lung receiving a dose of $\geq 20 \mathrm{~Gy}$; V30: The volume of the lung receiving a dose of $\geq 30 \mathrm{~Gy}$; V2 - LAV2: The volume of the lung without low attenuation volume receiving a dose of $\geq 2 \mathrm{~Gy}$; V5 - LAV5: The volume of the lung without low attenuation volume receiving a dose of $\geq 5 \mathrm{~Gy}$; V10 - LAV10: The volume of the lung without low attenuation volume receiving a dose of $\geq 10$ Gy; V20 LAV20: The volume of the lung without low attenuation volume receiving a dose of $\geq 20 \mathrm{~Gy}$; V30 - LAV30: The volume of the lung without low attenuation volume receiving a dose of $\geq 30 \mathrm{~Gy}$; V2\%: The percentage of lung volume irradiated with $\geq 2 \mathrm{~Gy}$; V5\%: The percentage of lung volume irradiated with $>5 \mathrm{~Gy}$; V10\%: The percentage of lung volume irradiated with $\geq 10 \mathrm{~Gy}$; V20\%: The percentage of lung volume irradiated with $\geq 20 \mathrm{~Gy}$; V30\%: The percentage of lung volume irradiated with $\geq 30 \mathrm{~Gy}$; (V2 - LAV2) / (TLV - LAV): The ratio of the lung without low attenuation volume receiving $\geq 2$ Gy to the total lung volume without low attenuation volume; (V5 - LAV5) / (TLV - LAV): The ratio of the lung without low attenuation volume receiving $\geq 5$ Gy to the total lung volume without low attenuation volume; (V10 LAV10) / (TLV - LAV): The ratio of the lung without low attenuation volume receiving $\geq 10$ Gy to the total lung volume without low attenuation volume; (V20 - LAV20) / (TLV - LAV): The ratio of the lung without low attenuation volume receiving $\geq 20$ Gy to the total lung volume without low attenuation volume; (V30 - LAV30) / (TLV $L A V$ ): The ratio of the lung without low attenuation volume receiving $\geq 30$ Gy to the total lung volume without low attenuation volume

\section{Acknowledgements}

Not applicable.

\section{Funding}

Not applicable.

\section{Availability of data and materials}

The datasets used and/or analysed during the current study are available from the corresponding author on reasonable request.

\section{Authors' contributions}

YU and YN were involved in study design, data acquisition, data analysis and interpretation, manuscript preparation. WS, HN, MY, MO, and EO contributed to the data collection and manuscript preparation. DK performed data analysis and validation. KN, KA, and TT were involved in imaging assessment and manuscript preparation. STM performed data analysis and statistical analysis. All authors read and approved the final manuscript.

\section{Ethics approval and consent to participate}

We obtained approval from the institutional review board.

\section{Consent for publication}

Obtained.

\section{Competing interests}

The authors declare that they have no competing interests.

\section{Publisher's Note}

Springer Nature remains neutral with regard to jurisdictional claims in published maps and institutional affiliations.

\section{Author details}

'Division of Respiratory Medicine, Department of Internal Medicine, Shiga University of Medical Science, Otsu, Shiga, Japan. ²Department of Radiology, Shiga University of Medical Science, Otsu, Shiga, Japan. ${ }^{3}$ Department of Medical Statistics, Shiga University of Medical Science, Otsu, Shiga, Japan. ${ }^{4}$ The Center for Data Science Education and Research, Shiga University, Hikone, Shiga, Japan. ${ }^{5}$ Department of Radiology, Shiga University of Medical Science Hospital, Otsu, Shiga, Japan. ${ }^{6}$ Division of Infection Control and Prevention, Shiga University of Medical Science Hospital, Otsu, Shiga, Japan. ${ }^{7}$ Health Administration Center, Shiga University of Medical Science, Otsu, Shiga, Japan.
}

Received: 29 June 2017 Accepted: 12 September 2017

Published online: 02 October 2017

\section{References}

1. Inoue T, Shiomi H, Oh RJ. Stereotactic body radiotherapy for stage I lung cancer with chronic obstructive pulmonary disease: special reference to survival and radiation-induced pneumonitis. J Radiat Res. 2015;56:727-34.

2. Kimura T, Togami T, Takashima H, Nishiyama Y, Ohkawa M, Nagata Y. Radiation pneumonitis in patients with lung and mediastinal tumours: a retrospective study of risk factors focused on pulmonary emphysema. Br J Radiol. 2012:85:135-41.

3. Sanuki N, Ono A, Komatsu E, et al. Association of computed tomographydetected pulmonary interstitial changes with severe radiation pneumonitis for patients treated with thoracic radiotherapy. J Radiat Res. 2012;53:110-6.

4. Rancati T, Ceresoli GL, Gagliardi G, Schipani S, Cattaneo GM. Factors predicting radiation pneumonitis in lung cancer patients: a retrospective study. Radiother Oncol. 2003;67:275-83.

5. Takeda A, Kunieda E, Ohashi T, et al. Severe COPD is correlated with mild radiation pneumonitis following stereotactic body radiotherapy. Chest. 2012; 141:858-66.

6. Wang J, Cao J, Yuan S, et al. Poor baseline pulmonary function may not increase the risk of radiation-induced lung toxicity. Int J Radiat Oncol Biol Phys. 2013;85:798-804

7. Tsujino K, Hashimoto T, Shimada T, et al. Combined analysis of V20, VS5, pulmonary fibrosis score on baseline computed tomography, and patient age improves prediction of severe radiation pneumonitis after concurrent chemoradiotherapy for locally advanced non-small-cell lung cancer. J Thorac Oncol. 2014;9:983-90.

8. Oetzel D, Schraube P, Hensley F, Sroka-Perez G, Menke M, Flentje M. Estimation of pneumonitis risk in three-dimensional treatment planning using dose-volume histogram analysis. Int J Radiat Oncol Biol Phys. 1995;33: 455-60.

9. Graham MV, Purdy JA, Emami B, et al. Clinical dose-volume histogram analysis for pneumonitis after 3D treatment for non-small cell lung cancer (NSCLC). Int J Radiat Oncol Biol Phys. 1999:45:323-9.

10. Hernando ML, Marks LB, Bentel GC, et al. Radiation-induced pulmonary toxicity: a dose-volume histogram analysis in 201 patients with lung cancer. Int J Radiat Oncol Biol Phys. 2001;51:650-9.

11. Kwa SL, Lebesque JV, Theuws JC, et al. Radiation pneumonitis as a function of mean lung dose: an analysis of pooled data of 540 patients. Int J Radiat Oncol Biol Phys. 1998:42:1-9.

12. Tsujino $K$, Hirota $S$, Endo $M$, et al. Predictive value of dose-volume histogram parameters for predicting radiation pneumonitis after concurrent chemoradiation for lung cancer. Int J Radiat Oncol Biol Phys. 2003;55:110-5.

13. Kim TH, Cho KH, Pyo HR, et al. Dose-volumetric parameters for predicting severe radiation pneumonitis after three-dimensional conformal radiation therapy for lung cancer. Radiology. 2005;235:208-15.

14. Kim DK, Hersh CP, Washko GR, et al. Epidemiology, radiology, and genetics of nicotine dependence in COPD. Respir Res. 2011;12:9.

15. Common Terminology Criteria for Adverse Events v. 4.03, National Cancer Institute, National Institute of Health. Rockville. 2009. http://evs.nci.nih.gov/ ftp1/CTCAE/CTCAE 4.03_2010-06-14_QuickReference_8.5x11.pdf Accessed 25 May 2017

16. Marks LB, Bentzen SM, Deasy JO, et al. Radiation dose-volume effects in the lung. Int J Radiat Oncol Biol Phys. 2010;76:S70-6.

17. Fay M, Tan A, Fisher R, Mac Manus M, Wirth A, Ball D. Dose-volume histogram analysis as predictor of radiation pneumonitis in primary lung cancer patients treated with radiotherapy. Int J Radiat Oncol Biol Phys. 2005; 61:1355-63.

18. Bjermer L, Franzen L, Littbrand B, Nilsson $K$, Angstrom T, Henriksson R. Effects of smoking and irradiated volume on inflammatory response in the lung of irradiated breast cancer patients evaluated with bronchoalveolar lavage. Cancer Res. 1990;50:2027-30.

19. Bjermer L, Cai Y, Nilsson K, Hellstrom S, Henriksson R. Tobacco smoke exposure suppresses radiation-induced inflammation in the lung: a study of bronchoalveolar lavage and ultrastructural morphology in the rat. Eur Respir J. 1993:6:1173-80.

20. Hoover DA, Capaldi DP, Sheikh K, et al. Functional lung avoidance for individualized radiotherapy (FLAIR): study protocol for a randomized, double-blind clinical trial. BMC Cancer. 2014;14:934. 
21. Yamaguchi S, Ohguri T, Matsuki Y, et al. Radiotherapy for thoracic tumors: association between subclinical interstitial lung disease and fatal radiation pneumonitis. Int J Clin Oncol. 2015;20:45-52.

22. Palma DA, Senan $\mathrm{S}$, Tsujino $\mathrm{K}$, et al. Predicting radiation pneumonitis after chemoradiation therapy for lung cancer: an international individual patient data meta-analysis. Int J Radiat Oncol Biol Phys. 2013;85:444-50.

23. Ueki N, Matsuo Y, Togashi Y, et al. Impact of pretreatment interstitial lung disease on radiation pneumonitis and survival after stereotactic body radiation therapy for lung cancer. J Thorac Oncol. 2015;10:116-25.

24. Gevenois PA, de Maertelaer V, De Vuyst P, Zanen J, Yernault JC. Comparison of computed density and macroscopic morphometry in pulmonary emphysema. Am J Respir Crit Care Med. 1995;152:653-7.

25. Hoffman EA, Ahmed FS, Baumhauer $\mathrm{H}$, et al. Variation in the percent of emphysema-like lung in a healthy, nonsmoking multiethnic sample. The MESA lung study. Ann Am Thoracic Soc. 2014;11:898-907.

26. Newman KB, Lynch DA, Newman LS, Ellegood D, Newell JD Jr. Quantitative computed tomography detects air trapping due to asthma. Chest. 1994;106:105-9.

27. Mets OM, van Hulst RA, Jacobs $C$, van Ginneken $B$, de Jong PA. Normal range of emphysema and air trapping on CT in young men. AJR Am J Roentgenol. 2012;199:336-40.

28. Schroeder JD, McKenzie AS, Zach JA, et al. Relationships between airflow obstruction and quantitative $C T$ measurements of emphysema, air trapping, and airways in subjects with and without chronic obstructive pulmonary disease. AJR Am J Roentgenol. 2013;201:W460-70.

29. Regan EA, Hokanson JE, Murphy JR, et al. Genetic epidemiology of COPD (COPDGene) study design. COPD. 2010;7:32-43.

\section{Submit your next manuscript to BioMed Central} and we will help you at every step:

- We accept pre-submission inquiries

- Our selector tool helps you to find the most relevant journal

- We provide round the clock customer support

- Convenient online submission

- Thorough peer review

- Inclusion in PubMed and all major indexing services

- Maximum visibility for your research

Submit your manuscript at www.biomedcentral.com/submit 